\title{
TIME-SERIES ANALYSIS OF NIGERIA RICE SUPPLY AND DEMAND: ERROR CORRECTION MODEL APPROACH
}

\author{
O. OJOGHO, P. O. ERHABOR, R. A. EGUARE AND J. AHMADU
}

(Received 29 March 2012; Revision Accepted 19 November 2012)

\begin{abstract}
The study examined a time-series analysis of Nigeria rice supply and demand with a view to determining any long-run equilibrium between them using the Error Correction Model approach (ECM). The data used for the study represents the annual series of 1960-2007 (47 years) for rice supply and demand in Nigeria, derived from the World Rice Statistics compiled by the International Rice Research Institute (IRRI, 2009). The order of integration and the level of co-integration were determined using the Augmented Dickey Fuller (ADF), Johansen co-integration and Granger causality test. The result of the descriptive statistics showed that rice supply and demand had means of 1.8 and 1.6 million metric tonnes respectively with a demand-supply lag of 0.18 million metric tons. The Trace test indicated one co-integrating equation at the 0.05 level of significance while the Granger causality ran one-way from supply to demand. The result of the ECM shows that the co-efficient of the short-run and long-run relationships between rice demand and supply were 1.102963 and -0.043497 respectively. There is disequilibrium between Nigeria rice supply and demand in the short-run but re-equilibrates at 0.043 . Thus, the more the demand for rice, the higher the production is expected in order to avoid any shortage, in the short-run, which though will always even out in the long-run. Nigeria rice supply-demand exhibit disequilibrium in the short-run but has a long-run equilibrium.
\end{abstract}

KEYWORDS: Rice, Integration, Co-integration, Unit-Root And Stationarity.

\section{INTRODUCTION}

Rice is consumed regularly in Nigerian urban and rural areas. It is among the Nigerian main staples constituting the largest share of the households' total food expenditure, in both rural and urban centres (Ojogho and Alufohai, 2010). Its demand in Nigeria has been increasing since the mid-1970 (Daramola, 2005). During the 1960's, Nigeria had a per capita annual rice consumption of $3 \mathrm{~kg}$ which increased to an average of $18 \mathrm{~kg}$ during the 1980's, reaching $22 \mathrm{~kg}$ in the latter half of the 1990's (FAO 2002, and Akpokodje, et al., 2001). Also, within the decade of the 1990's, Erenstien, et al (2003) reported a 14\% annual increase in the demand for rice in Nigeria, but is currently $32.0 \mathrm{Kg}$ and $25.8 \mathrm{Kg}$ per capita in urban and rural Nigeria respectively (Ojogho and Erhabor, 2011). With total annual rice production at about 2 million metric tons, it is the fourth largest cereal crop grown in the country behind sorghum, millet and maize (Babafada, 2003). However, since Nigeria also imports about 2.5-3.0 million metric tons of rice, total national consumption exceeds 5 million metric tons per year, or more than $30 \mathrm{~kg}$ per capita per annum (Akpokodje, et al 2001). This could suggest why the federal government committed a staggering N600 million in foreign exchange to milled rice import in 1985. Akpokodje, et al (2001) found out that whereas Nigeria spent only about US $\$ 100,000$ on rice importation in 1970 , by 1999 , the value of rice imports has risen to
US $\$ 259$ million. They further averred that between 1961 and 1999, Nigeria spent US $\$ 4$ billion, during the period alone, giving an annual average of US $\$ 102$ million, during the period. This suggests that there has been a rising demand-supply gap for rice in Nigerian rice economy. This raises a number of pertinent questions both in the policy circle and amongst researchers. They want to know the trend in rice supply and demand in Nigeria, whether they have time-varying means, timevarying variances or time-varying means and variance, can the gap between rice supply and demand ever be closed, or if rice demand will ever be more than its supply. It is well known that many economic time-series data are first-difference stationary. In general, a regression involving the levels of these I(1) series will produce misleading results, with conventional Wald tests for coefficient significance spuriously showing a significant relationship between unrelated series (Phillips 1986). Engle and Granger (1987) noted that a linear combination of two or more l(1) series may be stationary, or $I(0)$, in which case, the series are said to be co-integrated. Such a linear combination defines a co-integrating equation with co-integrating vector of weights characterizing the long-run relationship between the variables. When investigating for long-run equilibrium, it is appropriate to examine each series for evidence of non-stationarity in order to confirm that cointegration approach is the appropriate tool (Fossati et

O. Ojogho, Department of Agricultural Economics and Extension Services, Faculty of Agriculture and Agricultural Technology, Benson Idahosa University, Ugbor, Edo State, Nigeria.

P. O. Erhabor, Department of Agricultural Economics and Extension Services, Faculty of Agriculture and Agricultural Technology, Benson Idahosa University, Ugbor, Edo State, Nigeria.

R. A. Eguare, Department of Agricultural Economics and Extension Services, Faculty of Agriculture and Agricultural Technology, Benson Idahosa University, Ugbor, Edo State, Nigeria.

J. Ahmadu, Department of Agricultural Economics and Extension Services, Faculty of Agriculture, University of Benin, Benin City, Edo State, Nigeria. 
al., 2007). However, Error Correction Model (ECM) is not only appropriate for non-stationary time series models that are characterized by cointegration (Keele and DeBoeuf 2005). This paper, therefore, examined the trend in rice supply and demand in Nigeria with a view to examining the short- and long-run equilibrium. To achieve this, the study sought to determine the existence of co-integration relationship between the pair of the series using the Johansen (1988) trace statistics.

\section{Methods}

The data used for the study cover the annual series for 1960-2007 (47 years) annual rice supply and

$\Delta P_{\mathrm{t}}=\mu_{0}+\lambda P_{\mathrm{t}-1}+\sum_{i}^{k} \beta_{\mathrm{i}} \Delta P_{\mathrm{t}-1}+\bar{\varepsilon}_{\mathrm{t}}$

$\Delta C_{\mathrm{t}}=\alpha_{\mathrm{a}}+\rho C_{\mathrm{t}-1}+\sum_{i}^{k} Y_{\mathrm{i}} \Delta C_{\mathrm{t}-1}++\varepsilon_{\mathrm{t}}$

Where $\mathrm{C}$ is the consumption, $\mathrm{P}$ is the supply (production), is the differencing operator and $\varepsilon_{i}$ is a white noise process. The procedure requires that the non-stationary variable be differenced sequentially until it attains stationarity. Also, the Granger causality test

$$
\begin{aligned}
& P_{\mathrm{t}}=\theta_{0}+\theta_{1} P_{\mathrm{t}-1}+\cdots+\theta_{1} P_{\mathrm{t}-1}+\varphi_{1} C_{\mathrm{t}-1}+\cdots+\varphi_{1} C_{-1}+\varepsilon_{\mathrm{t}} \\
& C_{\mathrm{t}}=\theta_{0}+\theta_{1} C_{\mathrm{t}-1}+\cdots+\theta_{1} C_{\mathrm{t}-1}+\varphi_{1} P_{\mathrm{t}-1}+\cdots+\varphi_{1} P_{-l}+\bar{\varepsilon}_{\mathrm{t}}
\end{aligned}
$$

Co-integration techniques were used to establish valid relationships between the variables. Rice supply response was estimated at macro-level using secondary data and employing co-integration and error correction mechanism. Co-integration between rice supply and rice demand variables was tested using Johansen's Approach. A test for a suitable lag length to be included in the co-integration test was performed, because the results of co-integration tests can be quite sensitive to this (Hafer and Sheehan, 1991: Hai et al., 2004). The number of lags was selected by applying three different multivariate lag selection criteria: the Akaike information

$P_{\mathrm{t}}=\partial_{0}+\sum_{\mathrm{i}}^{k} \emptyset_{\mathrm{i}} P_{\mathrm{t}-1}+\varepsilon_{\mathrm{t}}$

$C_{\mathrm{t}}=\rho_{0}+\sum_{i}^{\mathrm{k}} \lambda_{i} C_{\mathrm{t}-1}+\varepsilon_{\mathrm{t}}$ demand in Nigeria. The data were derived from the World Rice Statistics compiled by the International Rice Research Institute (IRRI, 2009) and covered the period from 1960-2007. A time-series properties of the variables were conducted to determine the order of integration. In order to test the presence of unit root and other properties of time series data under investigation, two approaches were used, viz: graphical demonstration of variables and Augmented Dickey Fuller (ADF) test. The standard diagnostic Adjusted Dickey-Fuller (ADF) test statistics for unit root was used to test stationarity of the supply and demand series for Nigeria. The test equation is respectively of the form:

was conducted to determine how much of current rice demand can be explained by past values of rice demand and then to see whether adding lagged values of rice supply can improve the explanation. A bivariate regression used was of the form:

criterion (AIC), the Hannan-Quin information criterion (HQIC), and the Schwarz's Bayesian information criterion (SBIC). A vector auto-regression (VAR) on the differenced series was conducted and lag-length of the model with the least AIC, HQIC and SBIC values chosen as the appropriate lag length to be included in the cointegration test. The test started with a lag-length of 27 and then shortened till the least values of the AIC, HQIC and SBIC were obtained. A test of long-run equilibrium was done with the Johansen multivariate co-integration analysis.

Where $t=1,2, \ldots$ refers to the years 1960 to 2007; Pt and $C_{t}$ are $a n \times 1$ vector of the logarithmic rice production and consumption at time $t\left(P_{t}=P_{1 t}, P_{2 t}, \ldots, P_{n t}\right.$ and $\left.C_{t}=C_{1 t}, C_{2 t}, \ldots, C_{n t}\right) ; \phi_{i}$ and $\lambda_{i}$ are $n \times n$ matrices of the parameters; $P_{0}$ and $\delta_{0}$ are an $n \times 1$ vector of intercept terms; $\varepsilon_{t}$ is an $n \times 1$ vector of error terms assumed to be $\operatorname{NID}(0, \quad)$ and $k$ is the lag length.

The short- and long-run equilibrium was estimated using the Error Correction Model (ECM) using EngleGranger Two-step Procedure. The model was stated as:

$\Delta P_{\mathrm{t}}=\theta \Delta C_{\mathrm{t}}+\sigma\left[P_{\mathrm{t}-1}+\pi C_{\mathrm{t}-1}\right]+\epsilon_{\mathrm{t}}$

Where $P$ and $C$ retain their earlier meaning, refers to the first difference while the inclusion of the second term, $P_{\mathrm{t}-1}+\pi C_{\mathrm{t}-1}$ is the explicit formulation of the fact that we assume that $P$ and $C$ have a long-term equilibrium relationship. More specifically, we know that any change in $\mathrm{P}_{t}$ is a sum of two effects: the short-run impact of the change in $\mathrm{C}_{t}$ on $\mathrm{P}_{t}$ and the long-run impact of the deviation from the equilibrium value in period $t$ adjusted at each period at the rate, $\sigma$. Thus, $v$ captures the short-run relationship between $\mathrm{C}$ and $\mathrm{P}$. It indicates how $P$ and $P$ immediately change if $C$ goes up one period while $\sigma$ gives the rate at which the model reequilibrates i.e. the speed at which it returns to its equilibrium level. Formally, $\sigma$ tells us the proportion of 
the disequilibrium which is corrected with each passing period. This coefficient should be negative and less than the absolute value of one indicating its re-equilibrating properties. If $\sigma=0$, then the process never reequilibrates and if $\sigma=-1$, then re-equilibration occurs in one period.

\section{RESULTS AND DISCUSSION}

Table 1 shows the descriptive statistics for rice supply and demand time series used for the study. The Table shows that rice supply and demand had means of 1768792 tonnes and 1590063 tonnes respectively with demand-supply lag of 178729 tonnes. The reported probability is the probability that a Jarque-Bera statistic exceeds (in absolute value) the observed value under the null hypothesis; a small probability value leads to the rejection of the null hypothesis of a normal distribution. For the rice supply and demand series displayed in the Table, the hypothesis of normal distribution is thus accepted at the $1 \%$ and $5 \%$ significance level because the distributions are positively skewed, and flat (plattykurtic) relative to the normal as indicated by their kurtosis which are each less than 3.

The key relationship between rice supply and demand is shown in Fig (1). Figure (1a) shows the alternate lead and lag of rice supply and demand attaining their peaks and minimum at the same time. The figure shows that just before the oil boom, between 1960 and 1976, rice supply ranged for 360000 in 1960 to 611000 tonnes while demand ranged from 240000 to 500000 tonnes. Thus rice supply led rice demand with little or no change in the lead. After the oil boom, between 1976 and 1986 (about 10 years interval), the demand for rice (50000001040000 tonnes) significantly exceeded the production (360000 - 947000 tonnes). Though supply more than tripled it 1976 level, demand out-weighed it over the same time interval. Between late 1980s and the early part of 2000s, supply led demand again while between 2001 and 2005, rice demand was greater than supply but rice supply was greater than its demand from 2004 to 2007. It shows the trends in the demand and supply for rice in Nigeria, 1960-2007. The graph also shows that both the supply and demand seemed to be "trending" upward, demand for rice increasing with increase in rice supply, although with fluctuations. According to graphical demonstration, data series of rice supply and demand in their original form seemed to be non-stationary as it exhibited an upward trend whereas its graph in first difference form Figure (1b) showed it to be a stationary series. This suggests that the means of the two series have been changing which may continue for longer time than foreseen \{Figure (1c)\}. Figure (c) shows a forecast of rice supply and demand for Nigeria. It shows that beyond 2010, rice supply will permanently lead rice demand. This indicates that they either have time-varying means, time-varying variances or timevarying means and variance.

\section{Unit Root Test}

The results of the unit root test of the series are presented in Table 2. The results of the unit root test (with an intercept) of the variables indicates a t-statistics of 0.5242 and 1.1470 for rice supply and rice demand respectively but a corresponding t-critical values of $3.5777,-2.9252$ and -2.6007 at the $1 \%, 5 \%$ and $10 \%$ levels of significance at their level, according to MacKinnon (1996) one-sided p-values. When all the price series were differenced once, the results of the unit root test indicate that the null hypothesis of a unit root can be rejected at the $5 \%$ level of significance. In testing for the presence of unit root in the series in level form, the Augmented Dickey-Fuller (ADF) test (Dick and Fuller, 1981; Said and Dickey 1984) was employed as presented in Table 2 with lag equals 1 . The results indicate a t-statistics of -8.4914 and -7.5829 for rice supply and demand respectively but a corresponding tcritical of $-3.5812,-2.9266$ and -2.014 at the $1 \%, 5 \%$ and $10 \%$ levels of significance at their fist difference, according to MacKinnon (1996) one-sided p-values. Thus, the variables are non-stationary in their level form. In the first difference form, however, the null hypothesis that the variables are integrated of the order $l(1)$ is rejected as their ADF statistics are, in absolute terms, more than the critical values which are respectively 2.913 and 2.914. The Table also indicates that rice supply and demand series for Nigeria are integrated of order one, that is, I (1).

Table 3 shows the results of the lag selection-order for the various information criteria. The least values of $27.7450,27.7747$ and 27.8238 was observed at zero lag for demand while the least values of 28.3166, 28.3464, and 28.3961 were observed at one lag for rice supply on the basis of the Akaike's Information Criterion (AIC), Hannan-Quin Information Criterion (HQIC) and Schwarz's Bayesian Information Criterion (SBIC). Therefore, a zero-year of lag for consumption and one year of lag for supply were selected for the model.

Table 4 reports the results for the Johansen trace statistic ( $\lambda$ trace) test. The trace values at both none and at most 1 of 20.7301 and 3.4116 respectively were respectively higher and lower than their corresponding critical values at $5 \%$ level of significance. The Table also presents the results of the co-integration test involving the use of Johansen Maximum Likelihood test to determine the number of co-integrating relations. The Trace test indicates one co-integrating equation at the 0.05 level of significance. Thus, comparing the trace statistic with the corresponding critical values, it can be seen that the null hypothesis of no co-integrating relationship can be rejected at both the $5 \%$ significance level and the $1 \%$ level of significance for the quantity of rice supply and demand in Nigeria. This is also true with the maximum Eigen values. This may suggest a form of equilibrium relationship between rice supply and demand.

Table 5 shows the Granger causality test for rice demand and supply quantities. The results show that, with 46 observation after adjustment, the null hypothesis that production does not Granger cause consumption had an F-Statistics of 15.99 which is significant at $1 \%$ level while the hypothesis that consumption does not Granger cause production had a statistically not significant value of 1.39 . Thus, we cannot reject the hypothesis that consumption does not Granger cause 
production but we do reject the hypothesis that supply/production does not Granger cause demand/consumption. Therefore it appears that Granger causality runs one-way from supply/production to demand/consumption and not the other way. The study accept the hypothesis that rice supply (production) does not Granger cause rice demand (consumption) implying that Granger causality runs one-way from rice supply to rice demand and not the other way.

Table 6 shows the VAR estimates of the rice supplydemand for Nigeria. The results show that previous years of rice supply and demand explain $95.48 \%$ of the variation of rice supply in the current year. The rice supply and demand at one lag are significant at $5 \%$ level of significance both with supply as dependent variable and demand as dependent variable. With supply as the dependent variable, a unit increase in previous year rice demand increase current year rice supply by 0.28 while a corresponding unit increase in previous year rice supply increase current year rice supply by 0.77 . This is expected since both are time related and are affected by the same psychological demand and supply shifters.
Table 7 shows the estimates of the Error Correction Model for the study. The results show that one-lag difference in demand and difference between one-lag differences in supply and demand for rice explain $93.6 \%$ of the variation in rice supply at any period. The result also shows that the coefficients agree with a priori expectation. The short-run relationship between rice demand and supply is 1.102963 . The shows that rice supply and a change in rice supply would immediately change by 1.102963 metric tons if rice demand changed by one unit in any period in the short-run. In other words, if demand goes up by one unit in 2015, then rice supply and change in rice supply would go up 1.1 metric tons in 2015. Similarly, the long-run relationship between rice demand and supply is -0.043497 . Its negative sign implies that the model re-equilibrates in any given year while the absolute value $(0.043497)$ tells the rate at which this occurs. The 0.043497 shows the speed at which system returns to its equilibrium level. It tells the proportion of the disequilibrium which is corrected with each passing year. This implies that rice demand and supply are in equilibrium in the long-run.

Table 1: Descriptive Statistics for Rice Supply and Demand Series, 1960-2007

\begin{tabular}{lcc}
\hline Statistics & Production & Consumption \\
\hline Mean & 1768792 & 1590063 \\
Median & 930000 & 1223500 \\
Maximum & 5000000 & 4700000 \\
Minimum & 304000 & 204000 \\
Std. Dev. & 1479865 & 1371620 \\
Skewness & 0.594513 & 0.799021 \\
Kurtosis & 1.879163 & 2.461820 \\
Jaraue-Bera & 5.340117 & 5.686755 \\
Sum & 84902000 & 76323000 \\
\hline
\end{tabular}

Table 2: Univariate Stationarity Properties of the Variable Series

\begin{tabular}{llllll}
\hline & \multicolumn{2}{c}{ Levels } & \multicolumn{2}{c}{ First difference } \\
\hline Rice supDlv & 0.5242 & 0.9859 & -8.4914 & 0.0000 & 1 \\
Rice demand & 1.1470 & 0.9973 & -7.5829 & 0.0000 & 1 \\
\hline
\end{tabular}

MacKinnon critical value for the prices in level forms at $5 \%$ is -2.9130 . MacKinnon critical value for the prices in first differences at $5 \%$ is 2.9140 .

Table 3: Lag Selection Order Criteria.

\begin{tabular}{|c|c|c|c|c|c|c|}
\hline Lag & $\begin{array}{c}\text { AIC } \\
\text { Consumption }\end{array}$ & supply & $\begin{array}{c}\text { HQIC } \\
\text { Consumption }\end{array}$ & n supply & $\begin{array}{c}\text { SIC } \\
\text { Consumption }\end{array}$ & supply \\
\hline 0 & $27.7450^{\star}$ & 28.3498 & $27.7747^{\star}$ & 28.3794 & $27.8238^{*}$ & 28.4285 \\
\hline 1 & 27.7750 & $28.3166^{*}$ & 27.8047 & $28.3464^{*}$ & 27.8545 & $28.3961^{*}$ \\
\hline 2 & 28.0824 & 28.5076 & 28.1124 & 28.5680 & 28.1627 & 28.6714 \\
\hline
\end{tabular}


Table 4: Results of Johansen Co-integration Rank Tests

\begin{tabular}{|c|c|c|c|c|c|c|c|c|}
\hline \multirow[t]{2}{*}{$\mathrm{H}_{0}$} & \multirow[t]{2}{*}{$\mathrm{H}_{1}$} & \multirow{2}{*}{$\begin{array}{l}\text { Eigen } \\
\text { value }\end{array}$} & \multirow{2}{*}{$\begin{array}{l}\text { Trace } \\
\text { value }\end{array}$} & \multirow{2}{*}{$\begin{array}{c}\text { Max. } \\
\text { Eigen value }\end{array}$} & \multicolumn{2}{|c|}{$5 \%$ critical value } & \multicolumn{2}{|c|}{ Prob. ** } \\
\hline & & & & & Trace value & Max. Eigen & Trace value & Eigen \\
\hline$r=0$ & r 0 & 0.3082 & 20.7301 & 17.3185 & 15.4947 & 14.2646 & 0.0074 & 0.0159 \\
\hline$r \leq 1$ & r 1 & 0.0700 & 3.4116 & 3.4116 & 3.8415 & 3.8415 & 0.0647 & 0.0647 \\
\hline
\end{tabular}

${ }^{* \star}$ Mackinnon-Haug-Michelis (1999) $p$-values, $\mathrm{H}_{\circ}$ and $\mathrm{H}_{1}$ are the null and alternative hypothesis

Table 5: Granger causality test for Rice Supply and Demand Quantities

\begin{tabular}{cccc}
\hline Null Hypothesis & Observation & F-Statistics & Prob. \\
\hline PROD does not Granger Cause CONS & 46 & 15.9911 & $7 \mathrm{E}-06$ \\
CONS does not Granger Cause PROD & 46 & 1.39456 & 0.2595 \\
\hline
\end{tabular}

Table 6: Estimates for First-order Nigeria Rice Supply-demand VAR System 1960-2007

a. Dependent Variable: Rice supply

\begin{tabular}{lcccc}
\hline Variable & Lag & Coefficient & Standard error & t-statistics \\
\hline Production/supply & 1 & 0.774119 & 0.10467 & 7.39590 \\
consumption/demand & 1 & 0.279606 & 0.11344 & 2.46472 \\
Constant & & 56641.63 & 73930.10 & 0.76615 \\
R-square = $=.954842$ & & & & Adj R-square $=0.952789$ \\
\hline
\end{tabular}

b. Dependent Variable: Rice demand

\begin{tabular}{llccc}
\hline Variable & Lag & Coefficient & Standard error & t-statistics \\
\hline Production/supply & 1 & 0.280243 & 0.07089 & 3.05318 \\
consumption/demand & 1 & 0.744712 & 0.07683 & 9.69252 \\
Constant & & 7500.75 & 50071.8 & 0.14980 \\
R-square $=0.975853$ & & & Adi R-square $=0.974756$ \\
\hline
\end{tabular}

Table 7: Estimates of the Error Correction Model and the Associated Errors

\begin{tabular}{ccccc}
\hline Variable & Coefficient & Std. Error & t-Statistic & Prob. \\
\hline CONSUM(-1) & 1.102963 & 0.022817 & 48.33895 & 0.0000 \\
E(-1) & -0.043497 & 0.039509 & -1.100958 & 0.2755 \\
R-squared & 0.936282 & & & \\
Adjusted R-squared & 0.935165 & & & \\
\hline
\end{tabular}

Fig 1a: Graphical Presentation of Rice Supply and Demand Trend from 1960-2009

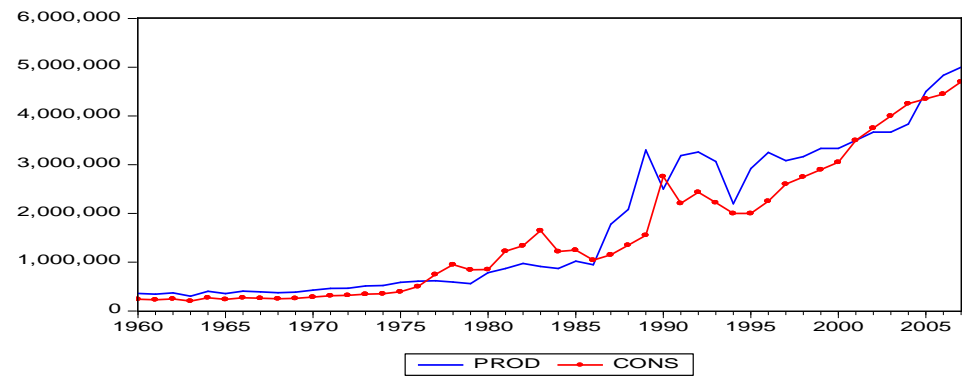


Fig 1b: Graphical Presentation of Rice Supply and Demand Trend in First Difference form.

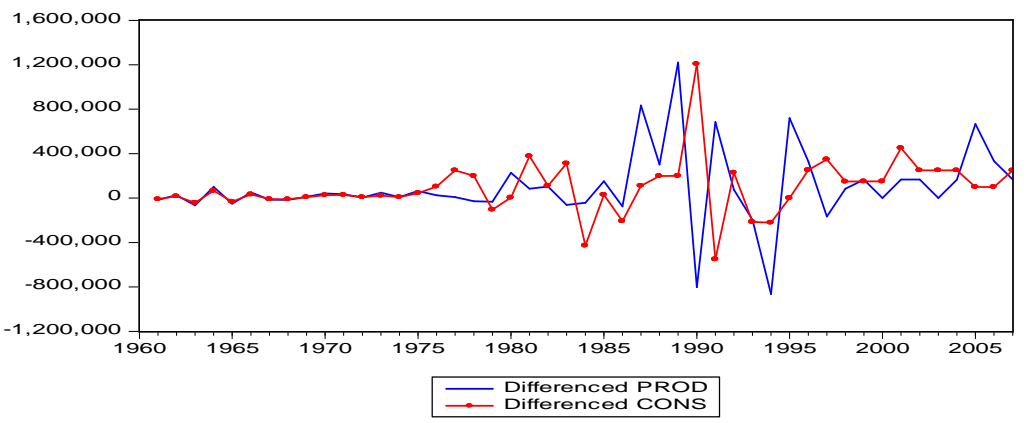

Fig 1c: Graphical Presentation of Rice Supply and Demand Trend from 1960-2019.

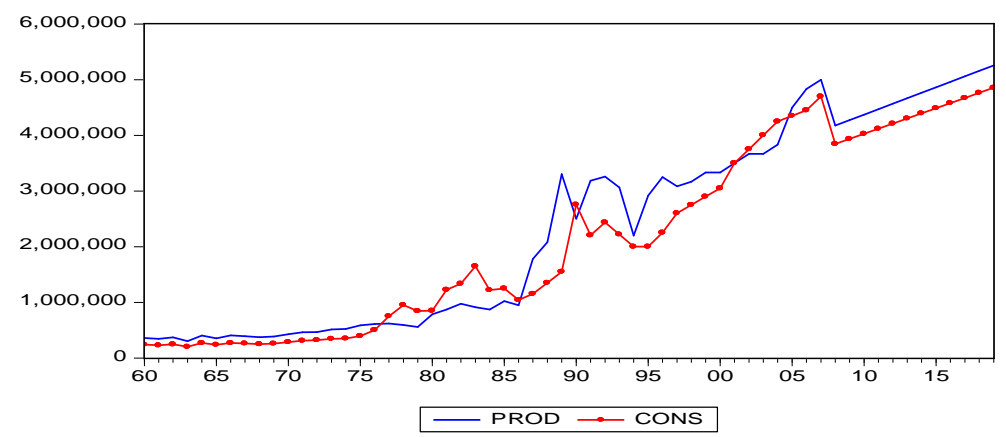

\section{CONCLUSION}

The study examined a time-series analysis of Nigeria rice supply and demand with a view to determining whether there is any long-run equilibrium between them using the annual series for 1960-2007 (47 years) which covered annual rice supply and annual rice demand from Nigeria derived from the World Rice Statistics, International Rice Research Institute (IRRI, 2009). The result showed, on average, a supply-demand lag over the period, that supply is driven by demand and that the two series are co-integrated. There is disequilibrium between supply and demand in the shortrun but re-equilibrates at 0.043 . Nigeria rice supplydemand exhibit disequilibrium in the short-run but a long-run equilibrium. Thus, the more the demand for rice, the higher the production is expected in order to avoid any lag in the short-run, which though will always even out in the long-run. This higher production can be achieved, however, by increase in domestic rice production through improved productivity and efficiency rather than through import.

\section{REFERENCES}

Akpokodje, G.; Lancon, F. and Erenstein, O., 2001. Nigeria's Rice Economy: State of the Art. The Nigeria Rice in a Competitive World: Constraints, Opportunities and strategic choices. Final Report Presented to West Africa Rice Development Association (WARDA), ouake, Cote'lvoire. Pp: 55

Babafada, M., 2003. Integrated Rice Production and Export in Nigeria. Paper presented at a Seminar on Sustainable rice production in Nigeria" organized by central bank of Nigeria held at hamadala hotel kaduna from $t$ January 14-15, 14.

Daramola, B., 2005. Government Policy and Competitiveness of Nigerian Rice Economy. Paper presented at the 'Workshop on Rice Policy and Food Security in Sub-Saharan Africa' organized by WARDA, Cotonou, Republic of Benin, November $7^{\text {th }}-9^{\text {th }}$.

Dickey, D. A. and Fuller, W. A., 1981. Likelihood ratio statistics for autoregressive time series with a unit root, Econometrica, 49:1057-72

Engle, R. F. and Granger, C. W. J., 1987. Cointegration and Error Correction: Representation, Estimation and Testing, Econometrica, 55, 251276. 
Erenstien, O., Lancon, F., Osiname, O. and Kebbeh, M., 2003. operational sing the strategic framework for rice sector revitalization in Nigeria, in: the Nigerian Rice Economy in a Competitive World, constraints, opportunities and strategic choices: West Africa Rice Development Association (WARDA). The Africa Rice Centre, Abidjan, Cted Ivoire: $38 \mathrm{pp}$

Food and Agriculture Organization., 2002. African Development Indicator. FAO, Rome.

Fossati, S.; Lorenzo, F. and Rodriguez, C. M., 2007. Regional and International market Integration of a Small Open Economy. J. Appl. Econ., 0: 7798, Universidad del CEMA,

Hafer, R. W and Sheehan, R. G., 1991. Policy Inference Using VAR Models. Econ. Enquiry, 29 (1): 4452. Oxford University Press.

Hai,, L. T. D; Lutz, C and Praagman, C., 2004. Rice Market Integration in the Mekong River Delta: the Successful Liberalisation of the Domestic Food Market in Vietnam. Research Report 04B10, University of Groningen, Research Institute, Systems, Organisation and Management (SOM).

International Rice Research Institute. (2009) World Rice Statistics. Johansen, S., 1988. Statistical Analysis of
Cointegrating Vectors. Journal of Economic Dynamics and Control, 12, 231-254.

Keele, L and DeBoeuf, S., 2005. "Taking Time Seriously: Dynamic Regression." Paper presented at the 2005 Annual Meeting of Political Methodology, Florida State University.

MacKinnon, J. G., 1996. "Numerical Distribution Functions for Unit Root and Cointegration Tests," Journal of Applied Econometrics, 11, 601-618.

Ojogho, O. and Alufohai, G. O., 2010. Impact of Price and Total Expenditure on Food Demand in South-Western Nigeria. African Journal of Food, Agriculture, Nutrition and Development, 10 (11): 4350-4363.

Ojogho, O and Erhabor, P. O., 2011. Rice Demand Pattern and It Intervening Factors in Nigeria. International Journal of Agricultural Research, 6(11): 769-779

Phillips, P. C. B., 1986. "Understanding spurious regressions in econometrics," Journal of Econometrics 33: 311- 340.

Said, S. E and Dickey D. A., 1984. Testing for unit roots in Autoregressive-moving average models of unknown order. Biometrika, 71: 599-607. 